\title{
Analysis of atmospheric neutral and charged molecular clusters in boreal forest using pulse-height CPC
}

\author{
K. Lehtipalo ${ }^{1}$, M. Sipilä ${ }^{1,2}$, I. Riipinen ${ }^{1}$, T. Nieminen ${ }^{1}$, and M. Kulmala ${ }^{1}$ \\ ${ }^{1}$ Department of Physics, P.O. Box 64, 00014 University of Helsinki, Finland \\ ${ }^{2}$ Helsinki Institute of Physics, P.O. Box 64, 00014 University of Helsinki, Finland
}

Received: 22 September 2008 - Published in Atmos. Chem. Phys. Discuss.: 10 December 2008

Revised: 26 May 2009 - Accepted: 10 June 2009 - Published: 23 June 2009

\begin{abstract}
We measured the size distribution of atmospheric neutral and charged clusters and particles down to mobility diameter around $1.5 \mathrm{~nm}$ by applying pulse-height CPC technique at SMEAR II station in Hyytiälä, southern Finland during spring 2007 and May 2008. The concentration of molecular clusters smaller than $3 \mathrm{~nm}$ seems to be highly variable in boreal forest environment, the concentration varied typically between $500-50000 \mathrm{~cm}^{-3}$. By comparing to concentrations measured with ion spectrometers, we conclude that ion clusters and neutral clusters produced by ion-ion recombination are usually not sufficient to explain all of the observed clusters; the median fraction of recombination products from all neutral clusters was $4.9 \%$. Before and during most new particle formation events the cluster formation rate rose only slightly, or remained close to stable. Nocturnal formation of clusters was also frequently observed.
\end{abstract}

\section{Introduction}

Aerosol particles affect the climate both directly by scattering and absorbing solar radiation and indirectly via cloud processes. The net radiative forcing of particles is currently believed to be negative (i.e. cooling), but the level of scientific understanding is still relatively low (IPCC, 2007). Detailed knowledge of nucleation process is needed to include secondary aerosol particles to climate models. Nucleation events have been proven to affect the regional and global particle budget significantly (Spracklen et al., 2006). Additionally, aerosol particles enter the human respiratory system,

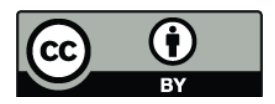

Correspondence to: K. Lehtipalo (katrianne.lehtipalo@helsinki.fi) where particles may cause adverse immediate and chronic health effects (e.g. Brunekreef and Holgate, 2002).

The existence of stable neutral atmospheric clusters and their role in new particle formation is the key question in understanding atmospheric nucleation process. New particle formation has been observed on numerous locations around the world (Kulmala et al., 2004a), but the exact mechanisms how particles are formed from precursor vapors are still under debate. The prevailing nucleation mechanism, at least in boreal forest environment, is suggested to be activation of neutral atmospheric clusters approximately $1-2 \mathrm{~nm}$ in diameter (Kulmala et al., 2000, 2006, and 2007a). Theoretical arguments and laboratory experiments support the existence of neutral clusters (e.g. Kulmala et al., 2005; Hanson and Eisele, 2002). The proposed candidates for the chemical compounds involved in forming clusters include sulphates (e.g. Vehkamäki et al., 2004; Kulmala et. al., 2004b), ammonia (Torpo et al., 2007) and organics (Bonn et al., 2008). Ion-ion recombination is also known to produce neutral clusters (Turco et al., 1998).

Due to instrumental limitations direct observations of neutral clusters in the atmosphere have been sparse. Weber et al. (1995) and Kulmala et al. (2005) showed that clusters were present during nucleation events. Ion clusters in the size range below $1.5 \mathrm{~nm}$ can be easily detected and have been proven to exist practically all time in the atmosphere (Horrrak et al., 1998). The concentration of ion clusters is, however, typically not high enough to explain the observed atmospheric particle formation rates (e.g. Laakso et al., 2004; Iida et al., 2006). The contribution of ion-induced nucleation to new particle formation in Hyytiälä seems to be less than 10\% (Gagné et al., 2008). A significant effort has recently been put into developing instruments capable of measuring neutral particles below $3 \mathrm{~nm}$, which is the lower detection

Published by Copernicus Publications on behalf of the European Geosciences Union. 
limit of the current commercial instruments. With newly developed measurement techniques, like Neutral Cluster and Air Ion Spectrometer (NAIS) and CPC-based applications, Kulmala et al. (2007a) and Sipilä et al. (2008, 2009) observed a persistent pool of neutral sub- $3 \mathrm{~nm}$ clusters in boreal forests.

In this work we will, for the first time, present a continuous time series of atmospheric neutral cluster concentrations. We also study the diurnal variation of cluster concentration in boreal forest, which gives insight into their production mechanisms. By measuring simultaneously both charged and neutral clusters with various independent instruments we aim at estimating the significance of ions in producing neutral clusters.

\section{Material and methods}

\subsection{Site description and instrumentation}

The measurements took place at SMEAR II station $\left(61^{\circ} 51^{\prime} \mathrm{N}, 24^{\circ} 17^{\prime} \mathrm{E}, 181 \mathrm{~m}\right.$ a.s.l.) in Hyytiälä, southern Finland. The station is surrounded by coniferous Scots pinedominated forest. For detailed site description see e.g. Hari and Kulmala (2005).

The particle size-distribution from 3 to $1000 \mathrm{~nm}$ was measured with a basic twin-DMPS system (Aalto et al., 2001). For measuring the ion mobility distribution a Balanced Scanning Mobility Analyzer (BSMA, Tammet, 2006) and an Air Ion Spectrometer (AIS, Mirme et al., 2007) were used. Both of the ion spectrometers are manufactured by Airel Ltd., and their mobility ranges are $0.032-3.2 \mathrm{~cm}^{2} \mathrm{~V}^{-1} \mathrm{~s}^{-1}(\sim 0.8-$ $7.6 \mathrm{~nm}$ in mobility diameter) and $0.0013-2.4 \mathrm{~cm}^{2} \mathrm{~V}^{-1} \mathrm{~s}^{-1}$ ( $\sim 0.9-42 \mathrm{~nm})$, respectively. Neutral Cluster and Air Ion Spectrometer (NAIS) is based on the AIS, but equipped with a unipolar charger to measure also neutral particles. The size range of the charger ions sets the lower size limit of the NAIS to about $2 \mathrm{~nm}$ depending on polarity and cluster concentration (Asmi et al., 2009). The size distribution of neutral and charged clusters $\sim 1.2-5 \mathrm{~nm}$ (equivalent ion mobility diameter) was measured with a pulse-height CPC (PH-CPC, discussed in Sect. 2.2).

During spring 2007 (15 March-26 June) all of the above mentioned instruments were measuring simultaneously in Hyytiälä as a part of the EUCAARI campaign (Kulmala et al., 2009). From spring 2008 (1-31 May) PH-CPC, DMPS and BSMA data were available. All particle measurements were conducted inside the forest canopy from a height of c. $2 \mathrm{~m}$ above the ground. All reported diameters are nonreduced mobility diameters, and all times are local wintertime.

\subsection{PH-CPC}

The pulse height analysis technique (Saros et al., 1996) relies on detecting the intensity of light scattered by particles after their condensational growth in the CPC. Due to supersaturation gradient inside the condenser, particles activate for growth at different axial positions depending on their size. The smaller the particle, the later it will be activated leading to smaller final droplet sizes. Clearly there is an upper size limit, after which only total concentration, but no size information of particles can be achieved, since all bigger particles are activated almost simultaneously. Pulse height analysis method has been used in size distribution measurements between 3 and $10 \mathrm{~nm}$ (Weber et al., 1995, 1998) as well as to determine the composition of freshly nucleated nanoparticles (O’Dowd et al., 2002; Hanson et al., 2002). Recently Sipilä et al. (2008) applied this method to detect atmospheric clusters.

The PH-CPC used in this study comprises a TSI-3025A ultrafine CPC with modified optics (Dick et al., 2000) and a multichannel analyzer. For increasing the detection efficiency of small particles, the supersaturation inside the condenser was increased from nominal until homogenous nucleation appeared. The pulse height analysis technique allowed us to distinguish homogenous nucleation from activation of clusters and resolve the size distribution of particles below $5 \mathrm{~nm}$. Detailed description of data inversion is published by Sipilä et al. (2009).

The PH-CPC's size response and detection efficiency has been calibrated using positive ions (silver and 241-Am charger generated ions) only, due to lack of reference instrument for neutral particles below $3 \mathrm{~nm}$. Winkler et al. (2008) showed that charged clusters are activated in lower supersaturations than neutral ones, and negative ones before positive. When PH-CPC is used for measuring atmospheric aerosol, we therefore tend to slightly underestimate the size and concentration of neutral particles. The activation probability of particles depends also on their composition (e.g. O'Down et al., 2002, 2003; Kulmala et al., 2007b). For these reasons the size scale of our results should not be considered as actual diameters, but rather the equivalent activation mobility diameter of insoluble positive ions.

Furthermore, the activation probability depends on the total particle concentration activated inside the condenser due to the vapour consumption of the growing droplets. At concentrations larger than $4000-5000 \mathrm{~cm}^{-3}$ homogenous nucleation is almost completely suppressed compromising the method. Cluster concentrations measured during strong nucleation events and pollution episodes are therefore not considered reliable, and normally excluded from the analyses. The factors affecting the size and concentration response of the PH-CPC are further discussed by Sipilä et al. (2009).

From spring 2007 to 2008 the measurement method was modified in a way that instead of assuming a symmetrical homogenous nucleation mode, we measured the homogenous 


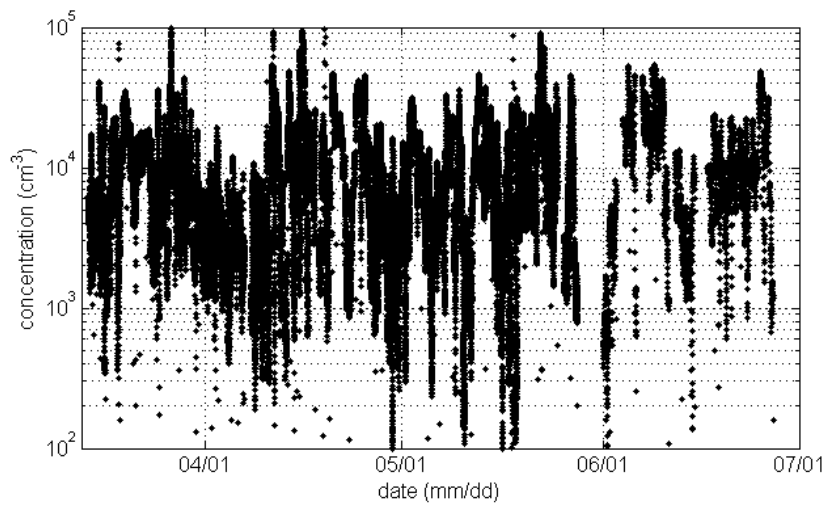

Fig. 1. Total number concentration of $<3 \mathrm{~nm}$ clusters measured with PH-CPC in Hyytiälä 14 March-26 June 2007.

nucleation level after each ambient measurement. For retaining a similar background concentration, a diffusion tube (c. $2 \mathrm{~m}$, i.d. $8 \mathrm{~mm}$ copper tubing, flow rate of $3 \mathrm{lpm}$ ) was applied for filtering the clusters and smallest particles away. Additionally, an ion trap $(7 \mathrm{~cm}$ coaxial tube i.d. $8 \mathrm{~mm}$ with a voltage of $32 \mathrm{~V}$ between the electrodes) was applied after each diffusion tube measurement to get rid of charged clusters. In 2007 the ion trap and a diffusion battery were applied irregularly.

\subsection{Data analysis}

\subsubsection{Neutral clusters}

In 2007 the concentration of neutral particles was calculated by subtracting the ion clusters of corresponding size range measured with the BSMA from the total cluster concentration measured with the PH-CPC. As the concentration of intermediate ions larger than $1.5 \mathrm{~nm}$ is typically very low, $<200 \mathrm{~cm}^{-3}$ except during nucleation events (Hirsikko et al., 2005), the effect should be minor. The neutral cluster concentration in 2008 can be achieved solely from PH-CPC data by subtracting the diffusion tube measurement from the ion trap measurements.

\subsubsection{Recombination products}

A neutral cluster may result if two ions of opposite charge collide and form a stable entity; this is called recombination. An estimate for the steady-state concentration of these recombination products can be obtained by setting the balance equation

$$
\begin{aligned}
& \frac{d N_{n, \text { rec }}}{d t}=a \alpha N_{i}^{+} N_{i}^{-} \beta N_{n, \text { rec }}\left(N_{i}^{+}+N_{i}^{-}\right) \\
& -\operatorname{CoagS}\left(N_{n, \text { rec }}\right) N_{n, \text { rec }}
\end{aligned}
$$

to zero. The subscript $n$ refers to neutral clusters and $i$ to ion clusters. $a$ is the fraction of stable recombination products, $\alpha$ the ion-ion recombination coefficient and $\beta$ the aerosol-ion

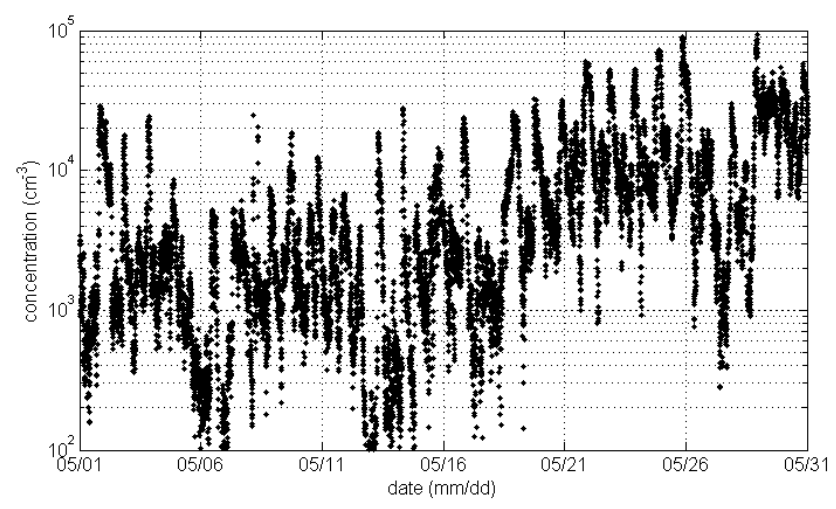

Fig. 2. Total number concentration of $<3 \mathrm{~nm}$ neutral clusters measured with PH-CPC in Hyytiälä 1-31 May 2008.

attachment coefficient. Thus the first term on the right hand side represents recombination source, the second and the third loss of neutral particles by charging and coagulation, respectively. For $\alpha$ we used a value of $1.6 \cdot 10^{-6} \mathrm{~cm}^{3} \mathrm{~s}^{-1}$ and for $\beta 0.01 \cdot 10^{-6} \mathrm{~cm}^{3} \mathrm{~s}^{-1}$ (Tammet and Kulmala, 2005). To obtain a maximum estimate, $a$ was set to unity. The ion cluster concentrations were taken from the BSMA data. As we were interested in recombination products in the size range of the PH-CPC, only collisions between ions large enough to produce particles about $1.5-2 \mathrm{~nm}$ in diameter were accounted for. The corresponding BSMA channels were chosen using mass-mobility relation by Mäkelä et al. (1996, based on experimental data by Kilpatrick, 1971).

\subsubsection{Formation rates}

The formation rate of $1.5 \mathrm{~nm}$ clusters can be calculated from (as in Kulmala et al., 2007a, supporting material)

$$
J_{1.5}=\frac{d N_{1.5-2}}{d t}+\operatorname{CoagS}_{1.5-2} \cdot N_{1.5-2}+\frac{G R_{1.5-2}}{0.5} N_{1.5-2}
$$

The coagulation loss is calculated for $2 \mathrm{~nm}$ particles from the DMPS data. We left the last term out, reaching again a minimum estimate for cluster formation rate. The equation can be written separately for neutral particles, ion clusters and for particles formed by recombination.

\section{Results and discussion}

\subsection{Cluster concentrations}

According to PH-CPC data from spring 2007 and May 2008, there is a pool of molecular clusters present in Hyytiälä practically all the time. Due to uncertainties regarding the size of these clusters discussed in Sect. 2.2, we hereafter usually refer to total concentration below $3 \mathrm{~nm}$, even though our measurements inevitably have a lower size limit corresponding to activation of positive $1.2 \mathrm{~nm}$ ions. Most probably we were able to see only the upper size section of 


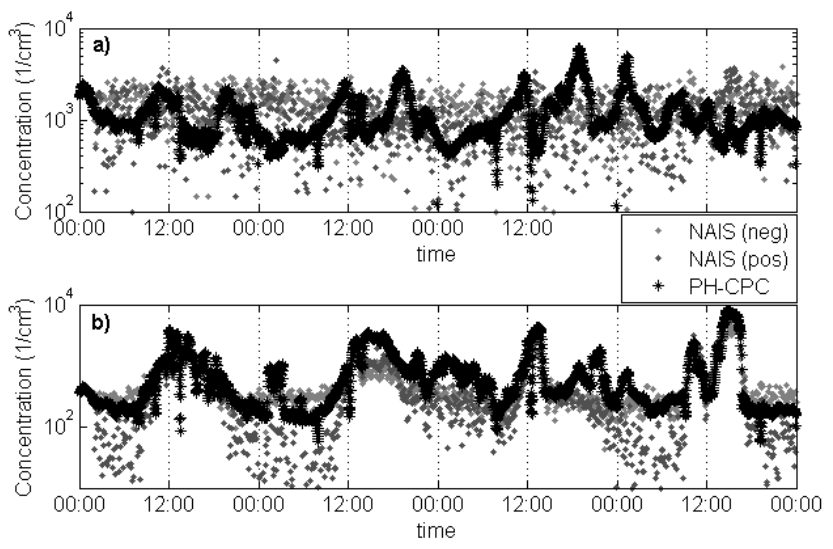

Fig. 3. Total number concentration of (a) clusters $1.5-3 \mathrm{~nm}$ and (b) particles 3-5 nm measured with PH-CPC (black stars) and NAIS (gray dots) on 31 March-3 April 2007 in Hyytiälä.
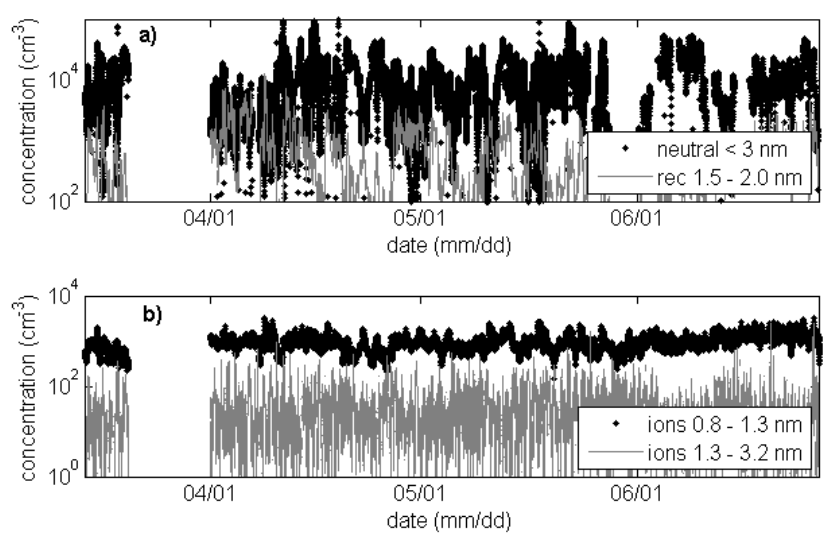

Fig. 4. (a) Number concentration of $<3 \mathrm{~nm}$ neutral clusters (black dots) and 1.5-2 nm recombination products (gray line), (b) concentration of ions $0.8-1.3 \mathrm{~nm}$ (black dots) and 1.3-3.2 nm (gray line). Data are calculated from PH-CPC and BSMA measurements in March-June 2007 in Hyytiälä.

the cluster band. Figure 1 presents the total cluster concentration from year 2007 and Fig. 2 neutral cluster concentration from 2008. The concentration of these clusters ranged from about $500 \mathrm{~cm}^{-3}$ to $50000 \mathrm{~cm}^{-3}$, the lowest values usually coinciding with high coagulation sink. The median (and 5- to 95-percentile) concentration of clusters below $3 \mathrm{~nm}$ was $8060 \mathrm{~cm}^{-3}\left(1510-31100 \mathrm{~cm}^{-3}\right)$ in spring 2007 and $3380 \mathrm{~cm}^{-3}\left(220-36300 \mathrm{~cm}^{-3}\right)$ in May 2008. In 2008 the homogenous nucleation level inside the PH-CPC was lower than in 2007 indicating lower supersaturation, which could partly explain the difference in median concentration, as we might have failed to activate the smallest clusters. When the temperature difference between saturator and condenser was increased on 15 May, we began to see slightly higher cluster concentrations. The median concentration on the second half of May (16-31 May 2008) is much closer to the value

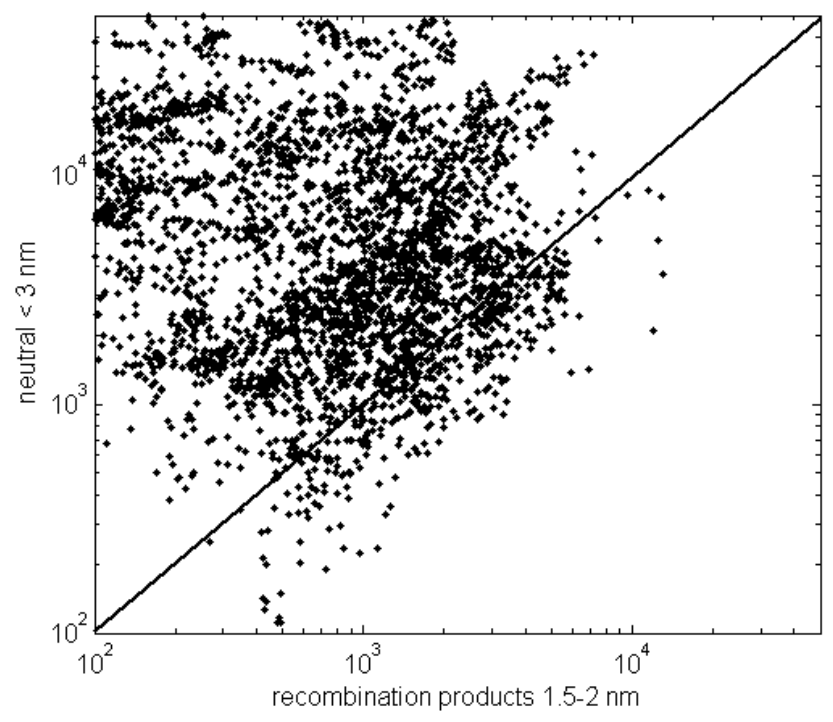

Fig. 5. Neutral $<3 \mathrm{~nm}$ clusters compared to $1.5-2 \mathrm{~nm}$ recombination products. Data are calculated from PH-CPC and BSMA measurements in April 2007 in Hyytiälä.

of $2007,9350 \mathrm{~cm}^{-3}\left(910-45000 \mathrm{~cm}^{-3}\right)$. However, as the concentration rises slowly rather than stepwise towards end of May, this is maybe only a part of the explanation. The variation in cluster concentration level might depend also on weather conditions, biological activity etc. Resolving the annual variation of clusters would, however, require longer continuous data sets.

In Fig. 3 we compared the total concentrations measured with the PH-CPC to the ones measured with the NAIS on 31 March-3 April 2007. In the size range 3-5 nm the measurement agree remarkably well, especially on the negative charging side of the NAIS. In the 1.5-3 nm range concentrations are of similar order, but either the NAIS is not sensitive enough to variations in cluster concentration or then again the PH-CPC detection efficiency is too sensitive to background aerosol concentration.

In Fig. 4 the fraction of neutral clusters from 2007 is compared to recombination products $(\sim 1.5-2 \mathrm{~nm})$ and ion cluster concentrations. It seems that the concentration of neutral clusters is one order of magnitude higher than recombination product and cluster ion $(\sim 0.8-1.3 \mathrm{~nm})$ concentrations, and two orders of magnitude higher than the concentration of ions of the corresponding size $(\sim 1.3-3.2 \mathrm{~nm})$. The scatter plot of neutral clusters as a function of recombination clusters, Fig. 5, further affirms, that we are able to see the 1.5$2 \mathrm{~nm}$ neutral particles produced by recombination, but that is not the single source of neutral clusters. The values below the unity line are explained by measurement noise and overestimation of recombination products. The median fraction of recombination clusters from all neutral clusters was $4.9 \%$, but the values varied from less than $0.1 \%$ to more than $100 \%$. This is in accordance with Kulmala et al. (2007a), 

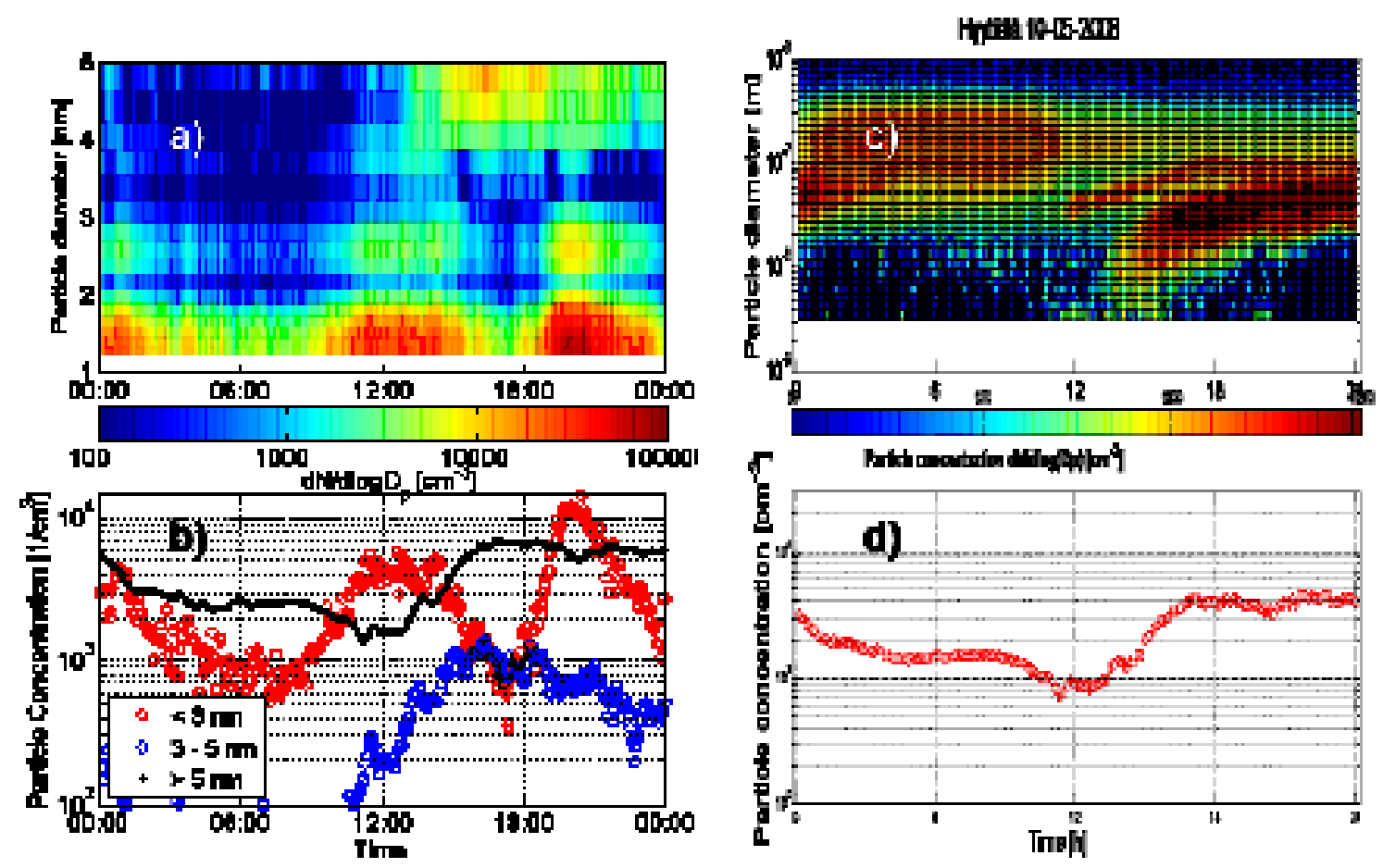

Fig. 6. Example of a new particle formation event day in Hyytiälä, 10 May 2008. (a) Number size distribution measured with PH-CPC, (b) total number concentration of $<3 \mathrm{~nm}$ neutral clusters (red circles), $3-5 \mathrm{~nm}$ particles (blue circles) and $>5 \mathrm{~nm}$ particles (black dots) measured with PH-CPC, (c) number size distribution measured with DMPS, (d) total number concentration measured with DMPS.

who calculated that recombination should usually account for less than $10 \%$ of neutral clusters in Hyytiälä conditions.

It is hard to give a certain accuracy estimate for our measurements, since clearly the uncertainties regarding size and concentration increase with decreasing particle size. As discussed in Sect. 2.2, most instrumental factors tend to lower the detection efficiency of clusters, so the concentration can be considered a minimum estimate. The measured cluster concentrations are indeed a bit lower than the ones predicted for Hyytiälä from formation rates of 2-3 nm particles, 7000$50000 \mathrm{~cm}^{-3}$ (Kulmala et al., 2007a). Sipilä et al. (2009) stated that the error in diameter due to unknown cluster composition and charge can be as large as $\sim 0.5 \mathrm{~nm}$ and the uncertainty in detection efficiency several percents.

\subsection{Particle formation}

An example of a new particle formation event on 10 May 2008 seen by the PH-CPC and DMPS is presented in Fig. 6. The number concentration of clusters starts to rise a little before 9 o'clock, and $3 \mathrm{~nm}$ particles appear about two hours later both in DMPS and PH-CPC. When total particle concentration reaches c. $4000 \mathrm{~cm}^{-3}$, the cluster concentration starts declining due to increased coagulation sink and declining supersaturation inside the instrument. In the evening a second process seems to take place, as the concentration of clusters rises again strongly peaking around 20 o'clock at $15000 \mathrm{~cm}^{-3}$. These nocturnal clusters reach the size of $\sim 3 \mathrm{~nm}$, but disappear gradually as they are scavenged mainly by coagulation (Kerminen et al., 2001). The upper range of these clusters is also visible in the DMPS figure just above the detection limit of the instrument.

No consistent pattern of cluster concentrations during nucleation events can be attained from the data. Clear growth from cluster band towards bigger particles was seen only rarely. Often the particles seemed to emerge at sizes close to 3-4 nm, and the cluster concentration rose simultaneously, or remained close to stable. This indicates that the actual particle formation might not happen in the near vicinity of our measurement place, but the air mass with newly formed particles is brought to the site by vertical or horizontal mixing. However, as strong particle formation changes the supersaturation inside the instrument rapidly, these events cannot be further studied using the present method.

The median diurnal variation of cluster concentration and neutral cluster formation rate is presented in Fig. 7 for spring 2007. Figure 8 presents median concentration of neutral clusters and 3-5 nm particles in May 2008. Days are classified into event, non-event and undefined days according to Dal Maso et al. (2005), excluding strong events with background aerosol concentration reaching over $5000 \mathrm{~cm}^{-3}$. Interestingly, the highest cluster concentrations were not measured during daytime nucleation events, but in the evenings 

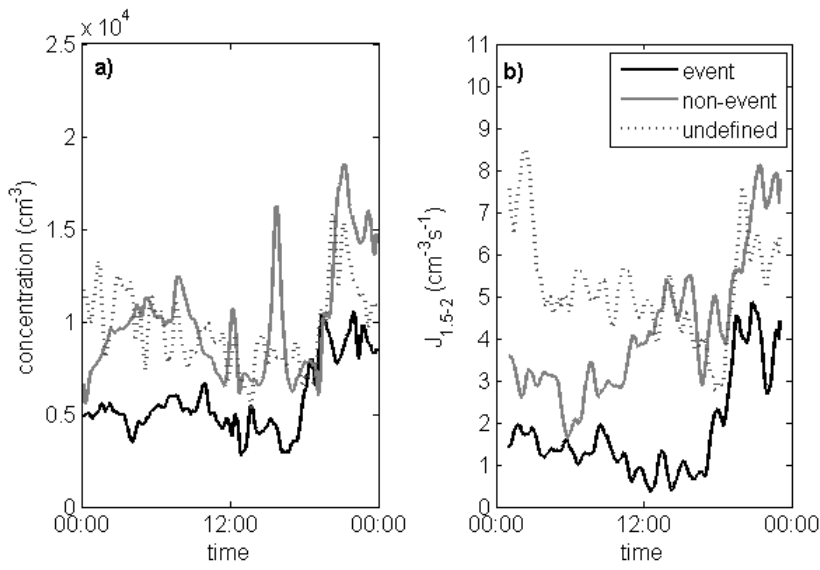

Fig. 7. Median diurnal variation of (a) total $<3 \mathrm{~nm}$ cluster concentration and (b) 1.5-2 nm neutral cluster formation rate in AprilMay 2007 in Hyytiälä. Days are classified into event (black line, 14 days), non-event (gray line, 8 days) and undefined (dashed line, 13 days) according to Dal Maso et al. (2005).
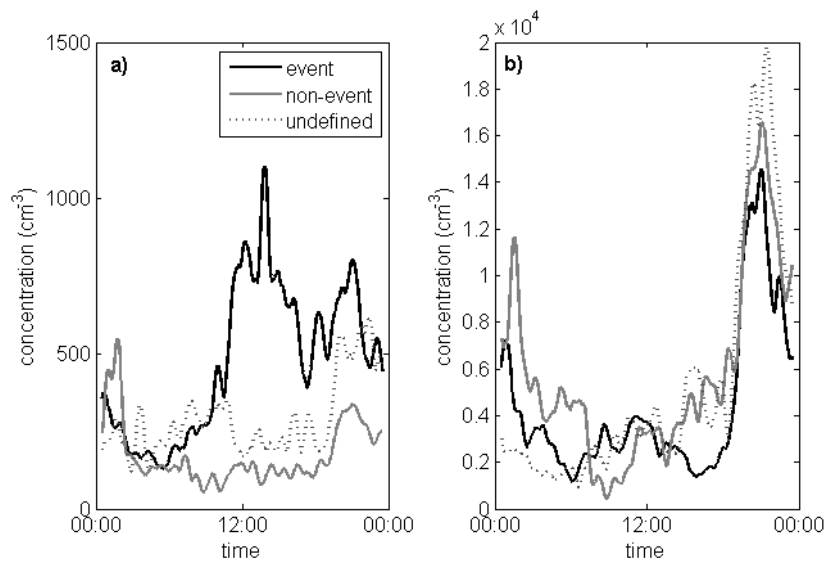

Fig. 8. Median diurnal variation of (a) 3-5 nm particle concentration and (b) $<3 \mathrm{~nm}$ neutral cluster concentration in May 2008 in Hyytiälä. Days are classified into event (black line, 16 days), nonevent (gray line, 2 days) and undefined (dashed line, 13 days) according to Dal Maso et al. (2005).

a little after sunset. This is partly due to lower night-time boundary layer, but as the formation rate and mean size also grew, we conclude, that there is a cluster source near ground in the night-time.

Favorable conditions for night-time cluster formation prevailed especially during late May 2008, as a distinct rise in concentration could be seen almost every night (Fig. 9). During this time period only weak (class II) events were observed in the daytime. Recently Junninen et al. (2008) studied nocturnal particle formation from ion data (AIS and BSMA) in Hyytiälä. They conclude that most strong nocturnal ion formation events are associated with rain, and that a nucleation event during daytime enhances particle formation in the
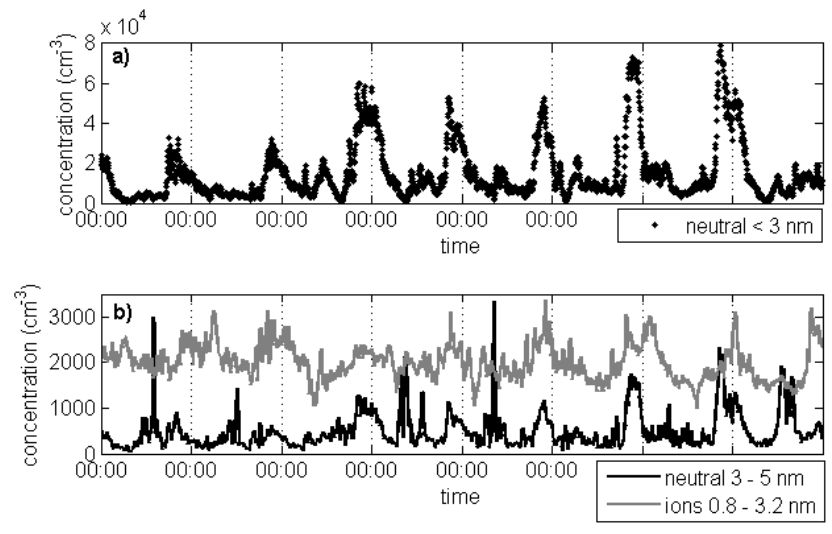

Fig. 9. Nocturnal cluster formation in Hyytiälä 19 May 200826 May 2008. Concentrations of (a) neutral $<3 \mathrm{~nm}$ clusters, (b) 3 $5 \mathrm{~nm}$ neutral particles (black line) and $0.8-3.2 \mathrm{~nm}$ ions (gray line).

following night. In the contrary, nocturnal formation of neutral clusters does not depend on rain and seems to be slightly higher on non-event days. The latter could although be a consequence of higher background concentration on event days. The characteristics of cluster formation was found to be very similar to the nocturnal event types identified by Junninen et al. (2008). Both the neutral and charged clusters persisted for hours and could sometimes reach sizes around $4-5 \mathrm{~nm}$, but never grew any larger. The simultaneous rise in ion cluster concentration was much less pronounced, which suggests that nocturnal growth of ion clusters could result mostly from charging of the neutral ones.

\section{Conclusions}

We observed number concentrations of molecular clusters ranging from less than a thousand to tens of thousands per cubic centimeter by directly measuring the cluster band in boreal forest environment during four months in spring 2007 and 2008. The size scale of PH-CPC measurements depends on the charge and composition of the measured particles. Since the concentration goes rapidly down after $\sim 2 \mathrm{~nm}$, we can nonetheless safely conclude, that the signal comes from clusters or molecules smaller than $3 \mathrm{~nm}$, which are thus beyond traditional aerosol instrumentation.

The data set presented in Sect. 3 is unique. Earlier reports on neutral clusters in boreal forest are mainly qualitative (Sipilä et al., 2008) or just examples from field are given (Sipilä et al., 2009). The measurements confirm the continuous existence of neutral clusters in Hyytiälä. Since the uncertainties regarding cluster concentrations are still large, the reported concentrations should be considered as our best estimates. However, the diurnal and day-to-day variation of clusters can be studied; a distinct diurnal variation with a clear night-time maximum was indeed found. 
The number of neutral clusters seems to considerably exceed the charged ones, as the measured cluster concentrations were usually at least one order of magnitude higher than total ion cluster concentrations. On most days, also the contribution of ion-ion recombination products to total neutral cluster concentration was found to be minor. For neutral clusters we cannot rely on any reference instrument, but the concentrations of 3-5 nm particles measured with PH-CPC correspond usually well to the NAIS and DMPS.

Our results support the concept that formation of clusters and their activation for growth are two distinct processes (Kulmala et al., 2000). Neutral clusters are readily formed in the night-time, when no particle formation is observed. The connection to daytime particle formation events remained still somewhat uncertain: on average the cluster concentration and formation rate remained close to stable during the event. The applicability of PH-CPC method to study new particle formation is however limited by its sensitivity to background aerosol concentration.

The PH-CPC was discovered to be suitable and stable enough for long-term field measurements. The primary advantages of using CPC and pulse-height-analysis method for detecting clusters are getting size information without a need to charge particles, and single-particle counting. However, we are operating on the very edge of the detection limit. The on-going development of new CPC-based instruments with lower cut-off size will draw upon these measurements. Improving the calibration methods for neutral particles below $3 \mathrm{~nm}$, and intercomparison with other instruments will also improve the reliability of the field measurements in future.

Acknowledgements. This work has been partially funded by European Commission 6th Framework programme project EUCAARI, contract no 036833-2 (EUCAARI), and by the Academy of Finland Center of Excellence program (project number 1118615). Maj and Tor Nessling foundation is acknowledged for financial support.

Edited by: A. Wiedensohler

\section{References}

Aalto, P., Hämeri, K., Becker, E., Weber, R., Salm, J., Mäkelä, J. M., Hoell, C., O’Dowd, C. D., Karlsson, H., Hansson, H.-C., Väkevä, M., Koponen, I. K., Buzorius, G., and Kulmala, M.: Physical characterization of aerosol particles in boreal forests, Tellus 53B, 344-358, 2001.

Asmi, E., Sipilä, M., Manninen, H. E., Vanhanen, J., Lehtipalo, K., Gagné, S., Neitola, K., Mirme, A., Mirme, S., Tamm, E., Uin, J., Komsaare, K., Attoui, M., and Kulmala, M.: Results of the first air ion spectrometer calibration and intercomparison workshop, Atmos. Chem. Phys., 9, 141-154, 2009, http://www.atmos-chem-phys.net/9/141/2009/.

Bonn, B., Kulmala, M., Riipinen, I., Sihto, S.-L., and Ruuskanen, T.: How biogenic terpenes govern the correlation between sulphuric acid concentrations and new particle formation, J. Geophys. Res., 113, D12209, doi:10.1029/2007JD009327, 2008.
Brunekreef, B. and Holgate, S.: Air pollution and health, Lancet, 360, 1233-1242, 2002.

Dal Maso, M., Kulmala, M., Riipinen, I., Wagner, R., Hussein, T., Aalto, P. P., and Lehtinen, K. E. J.: Formation and growth of fresh atmospheric aerosols: eight years of aerosol size distribution data from SMEAR II, Hyytiälä, Finland, Boreal Environ. Res., 10, 323-336, 2005.

Dick, W. D., McMurry, P. H., Weber, R. J., and Quant, R.: Whitelight detection for nanoparticle sizing with the TSI Ultrafine Condensation Particle Counter, J. Nanopart. Res., 2, 85-90, 2000.

Gagné, S., Laakso, L., Petäjä, T., Kerminen, V.-M., and Kulmala, M.: Analysis on one year of Ion-DMPS data from the SMEAR II station, Hyytiälä, Tellus, 60B, 318-329, 2008.

Hanson, D. R., Eisele, F. L., Ball, S. M., and McMurry, P. M.: Sizing small sulfuric acid particles with an ultrafine particle condensation nucleus counter, Aerosol Sci. Tech., 36, 554-559, 2002.

Hanson, D. R. and Eisele, F. L.: Measurement of prenucleation molecular clusters in the $\mathrm{NH}_{3}, \mathrm{H}_{2} \mathrm{SO}_{4}, \mathrm{H}_{2} \mathrm{O}$ system, J. Geophys. Res., 107(D12), 4158, doi:10.1029/2001JD001100, 2002.

Hari, P. and Kulmala, M.: Station for measuring ecosystematmosphere relations (SMEAR II), Boreal Environ. Res., 10, 315-322, 2005.

Hirsikko, A., Laakso, L., Hõrrak, U., Aalto, P. P., Kerminen, V.M., and Kulmala, M.: Annual and size dependent variation of growth rates and ion concentrations in boreal forest, Boreal Environ. Res., 10, 357-369, 2005.

Hõrrak, U., Salm, J., and Tammet, H.: Bursts if intermediate ions in atmospheric air, J. Geophys. Res., 103, 13909-13915, 1998.

Iida, K., Stolzenburg, M., McMurry, P., Dunn, M. J., Smith, J. N., Eisele, F., and Keady, P.: Contribution of ion-induced nucleation to new particle formation: Methodology and its application to atmospheric observations in Boulder, Colorado, J. Geophys. Res., 111, D23201, doi:1029/2006JD007167, 2006.

IPCC: Summary for Policymakers, in: Climate Change 2007: The Physical Science Basis, Contribution of Working Group I to the Fourth Assessment Report of the Intergovernmental Panel on Climate Change, edited by: Solomon, S., Qin, D., Manning, M., Chen, Z., Marquis, M., Averyt, K. B., Tignor, M., and Miller, H. L., Cambridge University Press, Cambridge, UK and New York, NY, USA, 2007.

Junninen, H., Hulkkonen, M., Riipinen, I., Nieminen, T., Hirsikko, A., Suni, T., Boy, M., Lee S.-H., Vana, M., Tammet, H., Kerminen, V.-M., and Kulmala, M.: Observations on nocturnal growth of atmospheric clusters, Tellus, 60B, 365-371, 2008.

Kerminen, V.-M., Pirjola, L., and Kulmala M.: How significantly does coagulational scavenging limit atmospheric particle production?, J. Geophys. Res., 106, 24119-24126, 2001.

Kilpatrick, W. D.: An experimental mass-mobility relation for ions in air at atmospheric pressure, Proc. Annu. Conf. Mass Spectosc., 19, 320-325, 1971.

Kulmala, M., Pirjola, L., and Mäkelä, J. M.: Stable sulphate clusters as a source of new atmospheric particles, Nature, 404, 66-69, 2000.

Kulmala, M.: How particles nucleate and grow?, Science, 302, 1000-1001, 2003.

Kulmala, M., Vehkamäki, H., Petäjä, T., Dal Maso, M., Lauri, A., Kerminen, V.-M., Birmili, W., and McMurry, P. H.: Formation and growth rates of ultrafine atmospheric particles: a review of 
observations, J. Aerosol Sci., 35, 143-176, 2004a.

Kulmala, M., Kerminen, V.-M., Anttila, T., Laaksonen, A., and O'Dowd, C. D.: Organic aerosol formation via sulphate cluster activation, J. Geophys. Res., 109, D04205, doi:10.1029/2003JD003961, 2004b.

Kulmala M., Lehtinen K. E. J., Laakso, L., Mordas, G., and Hämeri, K.: On the existence of neutral atmospheric clusters, Boreal Environ. Res., 10, 79-87, 2005.

Kulmala, M., Lehtinen, K. E. J., and Laaksonen, A.: Cluster activation theory as an explanation of the linear dependence between formation rate of $3 \mathrm{~nm}$ particles and sulphuric acid concentration, Atmos. Chem. Phys., 6, 787-793, 2006, http://www.atmos-chem-phys.net/6/787/2006/.

Kulmala, M., Riipinen, I., Sipilä, M., Manninen, H., Petäjä, T., Junninen, H., Dal Maso, M., Mordas, G., Mirme, A., Vana, M., Hirsikko, A., Laakso, L., Harrison, R. M., Hanson, I., Leung, C., Lehtinen, K. E. J., and Kerminen, V.-M.: Towards direct measurement of atmospheric nucleation, Science, 318, 89-92, supporting online material: www.sciencemag.org/cgi/content/full/ 1144124/DC1, 2007a.

Kulmala, M., Mordas, G., Petäjä, T., Grönholm, T., Aalto, P. P., Vehkamäki, H., Hienola, A. I., Herrmann, E., Sipilä, M., Riipinen, I., Manninen, H. E., Hämeri, K., Stratmann, F., Bilde, M., Winkler, P. M., Birmili, W., and Wagner, P. E.: The condensation particle counter battery (CPCB): A new tool to investigate the activation properties of nanoparticles, J. Aerosol Sci., 38, 289-304, 2007b.

Kulmala, M., Asmi, A., Lappalainen, H. K., Carslaw, K. S., Pöschl, U., Baltensperger, U., Hov, Ø., Brenquier, J.-L., Pandis, S. N., Facchini, M. C., Hansson, H.-C., Wiedensohler, A., and O'Dowd, C. D.: Introduction: European Integrated Project on Aerosol Cloud Climate and Air Quality interactions (EUCAARI) - integrating aerosol research from nano to global scales, Atmos. Chem. Phys., 9, 2825-2841, 2009,

http://www.atmos-chem-phys.net/9/2825/2009/.

Kulmala, M., Asmi, A., Lappalainen, H. K., Carslaw, K. S., Pöschl, U., Baltensperger, U., Hov, Ø., Brenguier, J.-L., Pandis, S. N., Facchini, M. C., Hansson, H.-C., Wiedensohler, A., and O'Dowd, C. D.: Corrigendum to "Introduction: European Integrated Project on Aerosol Cloud Climate and Air Quality interactions (EUCAARI) - integrating aerosol research from nano to global scales" published in Atmos. Chem. Phys., 9, 2825-2841, 2009, Atmos. Chem. Phys., 9, 3443-3444, 2009,

http://www.atmos-chem-phys.net/9/3443/2009/.

Laakso, L., Anttila, T., Lehtinen, K. E. J., Aalto, P. P., Kulmala, M., Hõrrak, U., Paatero, J., Hanke, M., and Arnold, F.: Kinetic nucleation and ions in boreal forest particle formation events, Atmos. Chem. Phys., 4, 2353-2366, 2004,

http://www.atmos-chem-phys.net/4/2353/2004/.

Mirme, A., Tamm, E., Mordas, G., Vana, M., Uin, J., Mirme, S., Bernotas, T., Laakso, L., Hirsikko, A., and Kulmala, M.: A wide-range multi-channel Air Ions Spectrometer, Boreal Environ. Res., 12, 247-264, 2007.

Mäkelä, J. M., Jokinen, V., Mattila, T., Ukkonen, A., and Keskinen, J.: Mobility distribution of acetone cluster ions, J. Aerosol Sci., 27, 175-190, 1996.

O’Dowd, C. D., Aalto, P., Hämeri, K., Kulmala, M., and Hoffmann, T.: Atmospheric particles from organic vapours, Nature, 416, 497-498, 2002.
O’Dowd, C. D., Aalto, P. P., Yoon, Y. J., and Hämeri, K.: The use of the pulse height analyzer ultrafine condensation particle counter (PHA-UCPC) technique applied to sizing of nucleation mode particles of different chemical composition, J. Aerosol Sci., 35(2), 205-216, 2003.

Saros, M., Weber, R. J., Marti, J., and McMurry, P. H.: Ultra fine aerosol measurement using a condensation nucleus counter with pulse height analysis, Aerosol Sci. Tech., 25, 200-213, 1996.

Sipilä, M., Lehtipalo, K., Kulmala, M., Petäjä, T., Junninen, H., Aalto, P. P., Manninen, H. E., Kyrö, E.-M., Asmi, E., Riipinen, I., Curtius, J., Kürten, A., Borrmann, S., and O'Dowd, C. D.: Applicability of condensation particle counters to measure atmospheric clusters, Atmos. Chem. Phys., 8, 4049-4060, 2008, http://www.atmos-chem-phys.net/8/4049/2008/.

Sipilä, M., Lehtipalo, K., Attoui, M., Neitola, K., Petäjä, T., Aalto, P. P., O'Dowd, C. D., and Kulmala, M.: Laboratory verification of PH-CPC's ability to monitor atmospheric sub-3 nm clusters, Aerosol Sci. Technol., 43, 2, 126-135, 2009.

Spracklen, D. V., Carslaw, K. S., Kulmala, M., Kerminen, V.-M., Mann, G. W., and Sihto, S.-L.: The contribution of boundary layer nucleation events to total particle concentrations on regional and global scales, Atmos. Chem. Phys., 6, 5631-5648, 2006, http://www.atmos-chem-phys.net/6/5631/2006/.

Tammet, H. and Kulmala, M.: Simulation tool for atmospheric aerosol nucleation bursts, J. Aerosol Sci., 36, 173-196, 2005.

Tammet, H.: Continuous scanning of the mobility and size distribution of charged clusters and nanometer particles in atmospheric air and the balanced scanning mobility analyzer BSMA, Atmos. Res., 82, 523-535, 2006.

Torpo, L., Kurtén, T., Vehkamäki, H., Laasonen, K., Sundberg, M.R., and Kulmala, M.: Significance of ammonia in atmospheric nanoclusters, J. Phys. Chem. A., 111(42), 10671-10674, 2007.

Turco, R., P., Zhao, J. X., and Yu, F.: A new source of tropospheric aerosols: Ion-ion recombination, Geophys. Res. Lett., 25, 635638, 1998.

Vehkamäki, H., Napari, I., Kulmala, M., and Noppel, M.: Stable ammonium bisulphate clusters in the atmosphere, Phys. Rev. Lett., 93, 148501-148504, 2004.

Weber, R. J., McMurry, P. H., Eisele, F. L., and Tanner, D. J.: Measurement of expected nucleation precursor species and 3-500-nm diameter particles at Mauna Loa observatory, Hawaii, J. Atmos. Sci., 52, 2242-2257, 1995.

Weber, R. J., Stolzenburg, M. R., Pandis, S. N., and McMurry, P. H.: Inversion of ultrafine condensation nucleus counter pulse height distributions to obtain nanoparticle $(\sim 3-10 \mathrm{~nm})$ size distributions, J. Aerosol Sci., 29, 601-615, 1998.

Winkler, P. M., Steiner, G., Vrtala, A., Vehkamäki, H., Noppel, M., Lehtinen, K. E. J., Reischl, G. P., Wagner, P. E., and Kulmala, M.: Heterogeneous nucleation experiments bridging scale from molecular ion clusters to nanoparticles, Science, 319, 1374 1377, 2008. 